\title{
A Two-Step Newton-Type Method for Solving System of Absolute Value Equations
}

\author{
Lei Shi, ${ }^{1}$ Javed Iqbal $\left(\mathbb{D},{ }^{2}\right.$ Muhammad Arif $\mathbb{D D}^{2},{ }^{2}$ and Alamgir Khan ${ }^{2}$ \\ ${ }^{1}$ School of Mathematics and Statistics, Anyang Normal University, Anyang 455002, China \\ ${ }^{2}$ Department of Mathematics, Abdul Wali Khan University, Mardan 23200, KPK, Pakistan \\ Correspondence should be addressed to Javed Iqbal; javedmath@gmail.com
}

Received 12 May 2020; Revised 11 November 2020; Accepted 27 November 2020; Published 17 December 2020

Academic Editor: Mahmoud Mesbah

Copyright ( 2020 Lei Shi et al. This is an open access article distributed under the Creative Commons Attribution License, which permits unrestricted use, distribution, and reproduction in any medium, provided the original work is properly cited.

In this paper, we suggest a Newton-type method for solving the system of absolute value equations. This new method is a two-step method with the generalized Newton method as predictor. Convergence of the proposed method is proved under some suitable conditions. At the end, we take several numerical examples to show that the new method is very effective.

\section{Introduction}

We consider the system of absolute value equations of the form:

$$
A x-|x|=b,
$$

where $A \in R^{n \times n}$ and $b \in R^{n}$ are known vectors and $|x|$ denotes the absolute values of the components of $x \in R^{n}$. The system of absolute value equations arises in optimization, the economies with institutional restrictions upon prices, the free boundary problems for journal bearing lubrication, and the network equilibrium problems, for example, see [1-12]. Mansoori and Erfanian [13] suggested a dynamic model to obtain the exact solution of equation (1). The development of multistep methods has gained popularity in the field of computational mathematics. Recently, several multistep methods are proposed to solve equation (1), for example, see [3-6].

In this paper, we present a Newton-type method for solving the system of absolute value equations. The new method is a two-step method where the well-known numerical quadrature technique is used in the corrector step. The Newton-type method is very simple and easy to implement in practice. The existence and uniqueness of solution shows the importance of the suggested method. The convergence of the new method is discussed in Section 3.
Numerical results prove that the Newton-type method is very effective for solving large systems.

For $x \in R^{n}$, consider

$$
\operatorname{sign}(x)= \begin{cases}-1, & \text { if } x<0, \\ 0, & \text { if } x=0, \\ 1, & \text { if } x>0 .\end{cases}
$$
fined as

The diagonal matrix $S$ corresponding to $\operatorname{sign}(x)$ is de-

$$
S(x)=\partial|x|=\operatorname{diag}(\operatorname{sign}(x))
$$

where $\partial|x|$ represents the generalized Jacobian of $|x|$. Note that $S(x) x=|x|$.

\section{Proposed Method}

Consider

$$
H(x)=A x-|x|-b .
$$

The generalized Jacobian of $H$ at $x$ is

$$
H^{\prime}(x)=\partial H(x)=A-S(x),
$$

where $S(x)$ is a diagonal matrix and $S(x) x=|x|$. We suggest the Newton-type method as 


$$
\begin{aligned}
y^{k} & =\left(A-S\left(x^{k}\right)\right)^{-1} b \\
x^{k+1} & =x^{k}-4\left(H^{\prime}\left(x^{k}\right)+2 H^{\prime}\left(\frac{x^{k}+y^{k}}{2}\right)+H^{\prime}\left(y^{k}\right)\right)^{-1} H\left(x^{k}\right), \quad k=0,1,2, \ldots
\end{aligned}
$$

The predictor step of equation (6) is the generalized Newton method [8], and the corrector step is the Trapezoidal method. The proposed method can be described as Algorithm 1.

\section{Convergence Analysis}

The predictor step is well defined (see Lemma 2 [8]):

$$
\begin{aligned}
H^{\prime}\left(x^{k}\right)+2 H^{\prime}\left(\frac{x^{k}+y^{k}}{2}\right)+H^{\prime}\left(y^{k}\right)= & A-S\left(x^{k}\right)+2 A-2 S\left(x^{k}+y^{k}\right) \\
& +A-S\left(y^{k}\right) \\
= & 4 A-S\left(x^{k}\right)-2 S\left(x^{k}+y^{k}\right)-S\left(y^{k}\right),
\end{aligned}
$$

which is nonsingular.

Lemma 1. If the singular values of $A \in R^{n \times n}$ exceed one, then $\left(4 A-S\left(x^{k}\right)-2 S\left(x^{k}+y^{k}\right)-S\left(y^{k}\right)\right)^{-1}$ exists for diagonal matrix $S$.

$$
y^{k}=\left(A-S\left(x^{k}\right)\right)^{-1} b
$$

Now, we want to prove that 


$$
E=H^{\prime}\left(x^{k}\right)+2 H^{\prime}\left(\frac{x^{k}+y^{k}}{2}\right)+H^{\prime}\left(y^{k}\right) .
$$

Then, equation (10) converts into

$$
\begin{aligned}
x^{k+1}= & x^{k}-4(E)^{-1} H\left(x^{k}\right), \\
E x^{k+1}= & E x^{k}-4 H\left(x^{k}\right) \\
= & E x^{k}-4\left(A x^{k}-\left|x^{k}\right|-b\right) \\
= & \left(4 A-S\left(x^{k}\right)-2 S\left(x^{k}+y^{k}\right)-S\left(y^{k}\right)\right) x^{k} \\
& -4\left(A x^{k}-S\left(x^{k}\right) x^{k}-b\right) \\
= & \left(3 S\left(x^{k}\right)-2 S\left(x^{k}+y^{k}\right)-S\left(y^{k}\right)\right) x^{k}+4 b
\end{aligned}
$$

or

$$
\begin{aligned}
( & \left.4 A-S\left(x^{k}\right)-2 S\left(x^{k}+y^{k}\right)-\left(y^{k}\right)\right) x^{k+1} \\
= & \left(3 S\left(x^{k}\right)-2 S\left(x^{k}+y^{k}\right)\right. \\
& \left.-S\left(y^{k}\right)\right) x^{k}+4 b .
\end{aligned}
$$

Lemma 2. The sequence in equation (6) is bounded and well defined if the singular values of $A$ exceed one. Hence, there exists an accumulation point $\dot{x}$ such that

$$
\begin{aligned}
& (4 A-\dot{S}(\dot{x})-2 \dot{S}(\dot{x}+t \dot{y})-\dot{S}(\dot{y})) \dot{x}=(3 \dot{S}(\dot{x})-2 \dot{S}(\dot{x} \\
& (A-\dot{S} \dot{x}) \dot{x}=b,
\end{aligned}
$$

for diagonal matrix $\dot{S}$.

Proof. Proof of this Lemma is similar to the proof of Proposition 3 of [8].

Now, we prove the main result about the convergence of the Newton-type method.

Theorem 1. If $\left\|\left(4 A-S\left(x^{k}\right)-2 S\left(x^{k}+y^{k}\right)-S\left(y^{k}\right)\right)^{-1}\right\|$ $<(1 / 12)$ for any diagonal matrix $S$ with diagonal entries of 0 or \pm 1 , then the Newton-type method converges to a solution $x^{*}$ of equation (1).
Proof. Consider

$$
\begin{aligned}
x^{k+1}-x^{*} & =x^{k}-4(E)^{-1} H\left(x^{k}\right)-x^{*}, \\
E\left(x^{k+1}-x^{*}\right) & =E\left(x^{k}-x^{*}\right)-4 H\left(x^{k}\right) .
\end{aligned}
$$

Since $x^{*}$ is the solution of equation (1), therefore

$$
H\left(x^{*}\right)=A x^{*}-\left|x^{*}\right|-b=0 .
$$

From equations 15 and (16), we have

$$
\begin{aligned}
E\left(x^{k+1}-x^{*}\right)= & E\left(x^{k}-x^{*}\right)-4 H\left(x^{k}\right)+4 H\left(x^{*}\right) \\
& =E\left(x^{k}-x^{*}\right)-4\left(H\left(x^{k}\right)-H\left(x^{*}\right)\right) \\
& =E\left(x^{k}-x^{*}\right)-4\left(A x^{k}-\left|x^{k}\right|-A x^{*}+\left|x^{*}\right|\right) \\
& =(E-4 A)\left(x^{k}-x^{*}\right)-4\left(\left|x^{*}\right|-\left|x^{k}\right|\right) \\
& =-\left(S\left(x^{k}\right)+2 S\left(x^{k}+y^{k}\right)+S\left(y^{k}\right)\right)\left(x^{k}-x^{*}\right)+ \\
& 4\left(\left|x^{k}\right|-\left|x^{*}\right|\right),
\end{aligned}
$$

or

$$
\begin{aligned}
x^{k+1}-x^{*}= & (E)^{-1}\left[4\left(\left|x^{k}\right|-\left|x^{*}\right|\right)-\left(S\left(x^{k}\right)+2 S\left(x^{k}+y^{k}\right)\right.\right. \\
& \left.\left.+S\left(y^{k}\right)\right)\left(x^{k}-x^{*}\right)\right] .
\end{aligned}
$$

Considering $C=S\left(x^{k}\right)+2 S\left(x^{k}+y^{k}\right)+S\left(y^{k}\right)$ yields

$$
\begin{aligned}
x^{k+1}-x^{*} & =(E)^{-1}\left[4\left(\left|x^{k}\right|-\left|x^{*}\right|\right)-C\left(x^{k}-x^{*}\right)\right], \\
\left\|x^{k+1}-x^{*}\right\| & \leq\left\|(E)^{-1}\right\|\left[8 x^{k}-x^{*}+\|C\|\left\|x^{k}-x^{*}\right\|\right] .
\end{aligned}
$$

In equation (19), we have used Lipschitz continuity of the absolute value (see Lemma 5 [8]); that is,

$$
\||x|-|y|\| \leq 2\|x-y\| .
$$

Since $S\left(x^{k}\right), S\left(y^{k}\right)$, and $2 S\left(x^{k}+y^{k}\right)$ are diagonal matrices with elements equal to \pm 1 or 0 , hence

$$
\|C\|=\left\|\left(S\left(x^{k}\right)+S\left(y^{k}\right)+2 S\left(x^{k}+y^{k}\right)\right)\right\| \leq\left\|S\left(x^{k}\right)\right\|+\left\|2 S\left(x^{k}+y^{k}\right)\right\|+\left\|S\left(y^{k}\right)\right\| \leq 4 \text {. }
$$

From equations (20) and (22), we have

$$
\left\|x^{k+1}-x^{*}\right\| \leq 12\left\|(E)^{-1}\right\|\left\|x^{k}-x^{*}\right\|<\left\|x^{k}-x^{*}\right\| .
$$

In equation (20), we have used the condition that $\left\|(E)^{-1}\right\|<1 / 12$. Hence, the sequence $\left\{x^{k}\right\}$ converges linearly to $x^{*}$. 
Corollary 1. Let $\left\|A^{-1}\right\|<(1 / 13)$ and $\left\|S\left(x^{k}\right)\right\|$, $\left\|S\left(y^{k}\right)\right\|$, and $\left\|2 S\left(x^{k}+y^{k}\right)\right\|$ are nonzero. Then, equation (1) is uniquely solvable for any $b$ and the Newton-type method is well defined and converges to the unique solution of equation (1) for any initial guess $x^{0}$.
Proof. The unique solvability of equation (1) for any $b$ requires that $\left\|A^{-1}\right\|<1 \quad[9] . \quad A^{-1}$ exists, and $\left\|(4 A)^{-1}\right\|\left\|S\left(x^{k}\right)+2 S\left(x^{k}+y^{k}\right)+S\left(y^{k}\right)\right\|<1$. By Banach perturbation lemma [14], we have

$$
\begin{aligned}
\left\|\left(H^{\prime}\left(x^{k}\right)+2 H^{\prime}\left(\frac{x^{k}+y^{k}}{2}\right)+H^{\prime}\left(y^{k}\right)\right)^{-1}\right\| & =\left\|\left(4 A-S\left(x^{k}\right)-2 S\left(x^{k}+y^{k}\right)-S\left(y^{k}\right)\right)^{-1}\right\| \\
& \leq \frac{\left\|(4 A)^{-1}\right\|\left\|S\left(x^{k}\right)+2 S\left(x^{k}+y^{k}\right)+S\left(y^{k}\right)\right\|}{1-\left\|(4 A)^{-1}\right\|\left\|S\left(x^{k}\right)+2 S\left(x^{k}+y^{k}\right)+S\left(y^{k}\right)\right\|} \\
& \leq \frac{(1 / 4)\left\|(A)^{-1}\right\| 4}{1-(1 / 4)\left\|(A)^{-1}\right\| 4}<\frac{(1 / 13)}{1-(1 / 13)}<\frac{1}{12} .
\end{aligned}
$$

Hence, by Theorem 1, the Newton-type method converges linearly to the solution of equation (1). This completes the proof.

Remark 1. In Section 4, for the last two examples $\left\|E^{-1}\right\|>(1 / 12)$, which shows that the Newton-type method may converge for $\left\|E^{-1}\right\|>(1 / 12)$. The convergence is guaranteed for $\left\|E^{-1}\right\|<(1 / 12)$.

\section{Numerical Results}

Now, we consider some numerical examples to show the performance of the new method. Let IT denote the number of iterations, RES is the residual, and CPU denotes the time in seconds. All the experiments are done with Intel(R) Core (TM)-5Y10c CPU @ $0.80 \mathrm{GHz} 1.00 \mathrm{GHz}, 4 \mathrm{~GB}$ RAM.

Example 1 (see [2]). Consider the matrix A as follows:

Rand ('state', 0$) ; \mathrm{R}=$ rand ( $\mathrm{m}, \mathrm{m}) ; \mathrm{A}=\mathrm{R}$ ' $* \mathrm{R}+\mathrm{m} *$ eye $(\mathrm{m}) ; \mathrm{b}=(\mathrm{A}-$ eye $(\mathrm{m}, \mathrm{m})) *$ ones $(\mathrm{m}, 1)$. (Matlab code) .

We compare the Newton-type method (NTM) with the generalized Traub method (GTM) [5] and improved generalized Newton method (INM) [2]. Numerical results are given in Table 1.

From the last column of Table 1, we conclude that the Newton-type method converges to the approximate solution of (1.1) with high accuracy.

Example 2 (see [2]). Consider the matrix A as follows:

$\mathrm{A}=\operatorname{round}(\mathrm{m} *($ eye $(\mathrm{m}, \mathrm{m})-0.02 *(2 * \operatorname{rand}(\mathrm{m}, \mathrm{m})-$ 1))); (MATLAB code). Choose a random $v \in R^{m}$ and $b=A \nu-|\nu|$.

We take $m=1000$ (problem size) and compare the Newton-type method (NTM) with the improved generalized Newton method (INM) [2] and the two-step iterative (TSI) method [3] graphically. Numerical results are illustrated in Figure 1.
Convergence curves show the efficiency of the proposed method. Figure 1 illustrates that the convergence of the NTM is better than other two methods.

Example 3. Consider the heat equation as follows:

$$
\frac{\partial r}{\partial t}(\mu, t)-\frac{\partial^{2} r}{\partial \mu^{2}}(\mu, t)-|r(\mu, t)|=0,0<\mu<1, t>0,
$$

with

$$
\begin{aligned}
& r(0, t)=r(1, t)=0, \\
& r(\mu, 0)=\mu(1-\mu), \quad 0 \leq \mu \leq 1 .
\end{aligned}
$$

We use the finite differences to approximate the solution of heat equation. Define the distance step-size $h=(1 / m)$ for $m>0$ and the time step-size $k$ such that $\mu_{i}=i h, i=1,2, \ldots, m-1$, and $t_{j}=j k, j=1,2, \ldots$, . The partial derivative at the grid point $\left(\mu_{i}, t_{j}\right)$ can be written as

$$
\begin{aligned}
\frac{\partial r}{\partial t}\left(x_{i}, t_{j}\right) & =\frac{r\left(\mu_{i}, t_{j}\right)-r\left(\mu_{i}, t_{j-1}\right)}{k}, \\
\frac{\partial^{2} r}{\partial \mu^{2}}\left(\mu_{i}, t_{j}\right) & =\frac{r\left(\mu_{i+1}, t_{j}\right)-2 r\left(\mu_{i}, t_{j}\right)+r\left(\mu_{i-1}, t_{j}\right)}{h^{2}} .
\end{aligned}
$$

Comparison of equation (6) with Maple solutions is given in Figure 2.

Example 4 (see [6]). Consider

$$
A=\operatorname{tridiag}(-1,4,-1) \in R^{n \times n}, x^{*}=\left((-1)^{l}, \quad l=1 \ldots, n\right)^{T} \in R^{n},
$$

and $b=A x^{*}-\left|x^{*}\right|$.

In this example, we compare the Newton-type method with the SOR-like method [6] and NINA [15]. Comparison 
Step 1: select an initial guess $x^{(0)} \in R^{n}$

Step 2: start for $k$ compute

$y^{k}=\left(A-S\left(x^{k}\right)\right)^{-1} b$

Step 3: using $y^{k}$ compute

$x^{k+1}=x^{k}-4\left(H^{\prime}\left(x^{k}\right)+2 H^{\prime}\left(x^{k}+y^{k} / 2\right)+H^{\prime}\left(y^{k}\right)\right)^{-1} H\left(x^{k}\right)$

Step 4: if $x^{k+1}=x^{k}$, then stop. If not, then put $k=k+1$ and turn back to step 2

\section{Algorithm 1}

TABle 1: Numerical results for Example 1.

\begin{tabular}{|c|c|c|c|c|c|c|c|c|c|}
\hline \multirow{2}{*}{ Dim } & \multicolumn{3}{|c|}{ GTM } & \multicolumn{3}{|c|}{ INM } & \multicolumn{3}{|c|}{ NTM } \\
\hline & IT & RES & $\mathrm{CPU}$ & IT & RES & $\mathrm{CPU}$ & IT & RES & $\mathrm{CPU}$ \\
\hline 100 & 3 & $1.1360 e-11$ & 0.0282 & 3 & $1.2528 e-11$ & 0.0248 & 2 & $7.0174 e-12$ & 0.0103 \\
\hline 200 & 3 & $8.0510 e-11$ & 0.0576 & 3 & $6.7278 e-11$ & 0.0428 & 2 & $1.2964 e-12$ & 0.0198 \\
\hline 300 & 3 & $2.8067 e-10$ & 0.0626 & 3 & $2.6026 e-10$ & 0.0504 & 2 & $3.3819 e-12$ & 0.0206 \\
\hline 400 & 3 & $6.8738 e-10$ & 0.1167 & 3 & $5.7847 e-10$ & 0.1021 & 2 & $7.4447 e-12$ & 0.1016 \\
\hline 500 & 3 & $1.1259 e-09$ & 0.2282 & 3 & $1.1792 e-09$ & 0.2191 & 2 & $1.1013 e-11$ & 0.2178 \\
\hline 600 & 3 & $2.1310 e-09$ & 0.3412 & 3 & $2.4023 e-09$ & 0.3273 & 2 & $4.5880 e-11$ & 0.3156 \\
\hline 700 & 3 & $2.9880 e-09$ & 0.3846 & 3 & $3.6051 e-09$ & 0.3685 & 2 & $4.9918 e-11$ & 0.3512 \\
\hline 800 & 4 & $5.1658 e-09$ & 0.5311 & 3 & $3.8475 e-09$ & 0.4015 & 2 & $6.2056 e-11$ & 0.3951 \\
\hline 900 & 4 & $6.9541 e-09$ & 0.6891 & 3 & $7.0228 e-09$ & 0.4236 & 2 & $1.4251 e-10$ & 0.4187 \\
\hline 1000 & 4 & $8.8558 e-09$ & 0.8616 & 3 & $7.3382 e-09$ & 0.5513 & 2 & $1.3938 e-10$ & 0.4563 \\
\hline
\end{tabular}

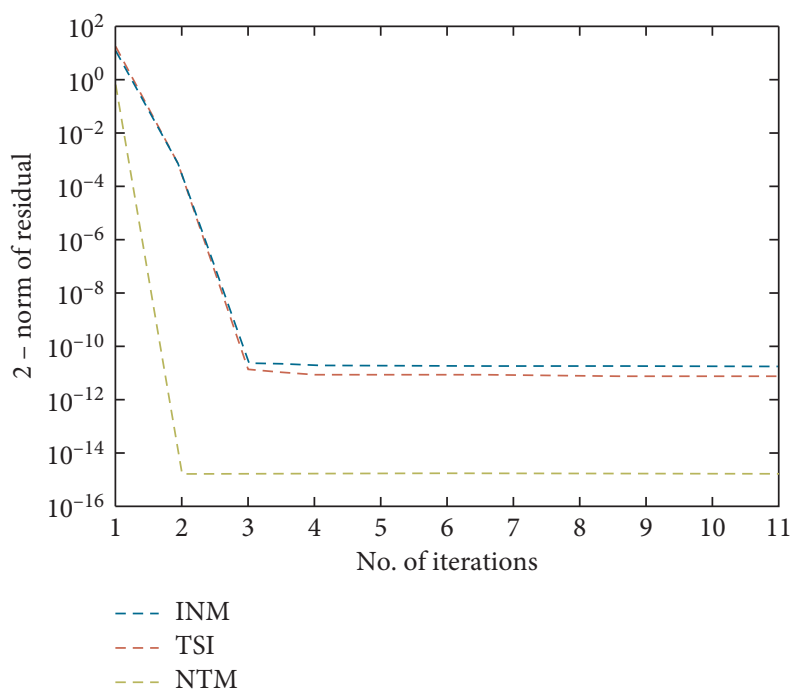

FIgure 1: Convergence curves of different methods. 


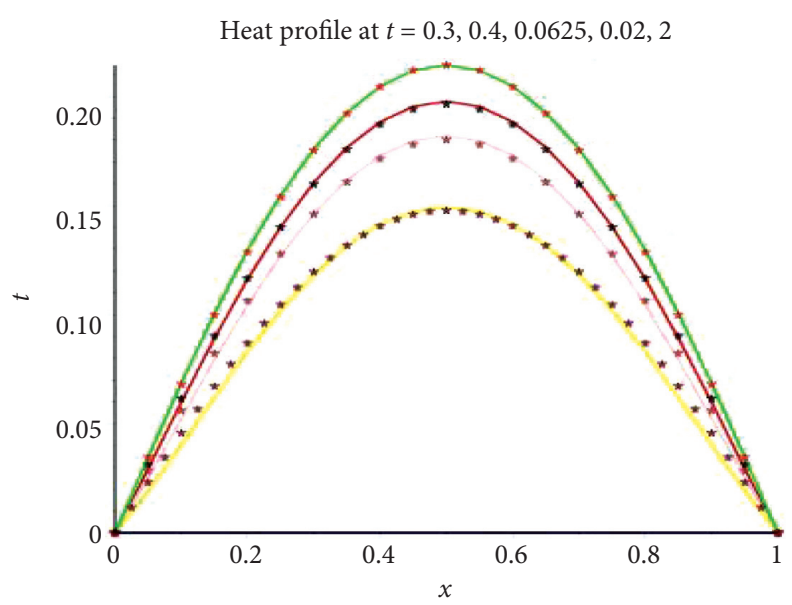

Figure 2: Convergence curves of different methods.

TABle 2: Numerical results for Example 4.

\begin{tabular}{|c|c|c|c|c|c|c|c|}
\hline Method & $n$ & 1000 & 2000 & 3000 & 4000 & 5000 & 6000 \\
\hline \multirow{4}{*}{ NINA } & IT & 18 & 18 & 18 & 18 & 18 & 18 \\
\hline & $\begin{array}{c}\text { RES } \\
\text { ER }\end{array}$ & $3.4947 e-07$ & $4.9580 e-07$ & $6.0786 e-07$ & $7.0227 e-07$ & $7.8541 e-07$ & $8.6055 e-07$ \\
\hline & $\begin{array}{c}\mathrm{R} \\
\mathrm{CP}\end{array}$ & $1.8652 e-07$ & $2.6468 e-07$ & $3.2453 e-07$ & $3.7494 e-07$ & $4.1934 e-07$ & $4.5946 e-07$ \\
\hline & $\mathrm{U}$ & 139.2571 & 879.3143 & 3083.7005 & - & - & - \\
\hline \multirow{4}{*}{ SOR-like- } & $\mathrm{IT}$ & 15 & 16 & 16 & 16 & 16 & 17 \\
\hline & $\begin{array}{c}\text { RES } \\
\text { ER }\end{array}$ & $9.8477 e-07$ & $6.3197 e-07$ & $7.7428 e-07$ & $8.9422 e-07$ & $9.9988 e-07$ & $2.0134 e-07$ \\
\hline & $\begin{array}{c}\mathrm{R} \\
\mathrm{CP}\end{array}$ & $4.4031 e-07$ & $7.7428 e-07$ & $1.2729 e-07$ & $1.4701 e-07$ & $1.6438 e-07$ & $9.0038 e-08$ \\
\hline & $\mathrm{U}$ & 0.9999 & 7.0482 & 23.4849 & 54.02271 & 104.1137 & 178.4376 \\
\hline \multirow{4}{*}{ NTM } & IT & 2 & 2 & 2 & 2 & 2 & 2 \\
\hline & $\begin{array}{c}\text { RES } \\
\text { ER }\end{array}$ & $1.1960 e-11$ & $3.5203 e-11$ & $6.3912 e-11$ & $9.6775 e-11$ & $1.4111 e-10$ & $1.7906 e-10$ \\
\hline & $\begin{array}{c}\mathrm{R} \\
\mathrm{CP}\end{array}$ & $3.2890 e-12$ & $9.3320 e-12$ & $1.6375 e-11$ & $2.5658 e-11$ & $3.5328 e-11$ & $4.4462 e-11$ \\
\hline & $\mathrm{U}$ & 0.7966 & 5.3339 & 18.0749 & 41.8621 & 80.8494 & 137.7330 \\
\hline
\end{tabular}

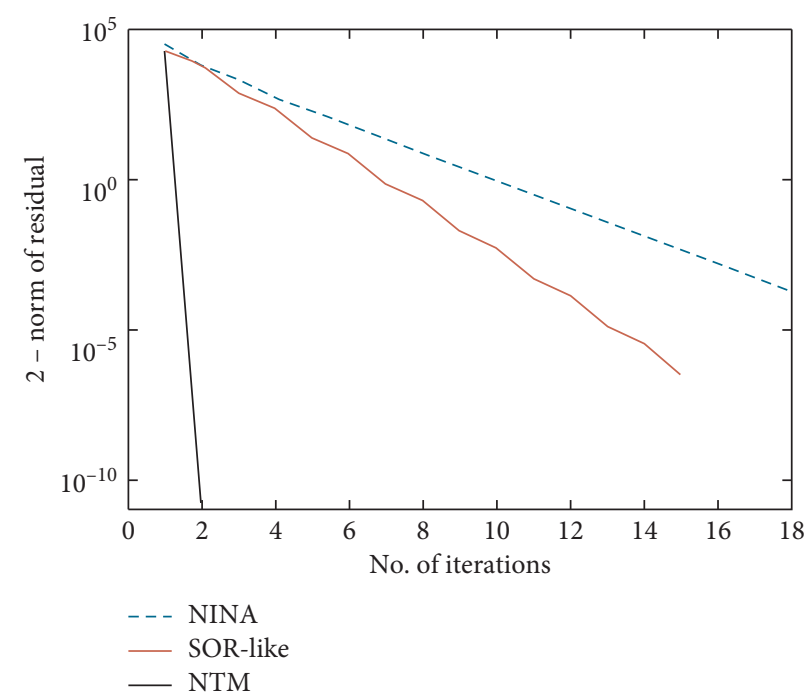

FIgURE 3: Convergence curves of different methods. 
is given in Table 2, where $\mathrm{ERR}=\left\|x^{k}-x^{*}\right\|$ and $x^{*}$ is the exact solution.

Table 2 shows that NTM converges to the solution in just 2 iterations with high accuracy.

We take $n=1000$ (problem size) and compare the Newton-type method (NTM) with the SOR-like method [6] and NINA [11] graphically in Figure 3.

\section{Conclusion}

In this paper, we developed the Newton-type method for solving the system of absolute value equations. This new iterative method is very simple and easy to implement. The future work is to extend this idea by taking more than three points in the corrector step. The numerical results show the efficiency and accuracy of the proposed method.

\section{Data Availability}

The data used to support the findings of this study are available from the corresponding author upon request.

\section{Conflicts of Interest}

The authors declare that they have no conflicts of interest.

\section{Acknowledgments}

This research was supported by the HEC Pakistan Research, grant no. 1003/SRGP/R\&D/HEC2016.

\section{References}

[1] V. Edalatpour, D. Khojasteh, and D. K. Salkuyeh, "A generalization of the Gauss-Seidel iteration method for solving absolute value equations," Applied Mathematics and Computation, vol. 293, pp. 156-167, 2017.

[2] J. Feng and S. Liu, An Improved Generalized Newton Method for Absolute Value Equations, Springer, Berlin, Germany, 2016.

[3] J. Feng and S. Liu, "A new two-step iterative method for solving absolute value equations," Journal of Inequalities and Applications, vol. 2019, no. 1, 2019.

[4] P. Guo, S.-L. Wu, and C.-X. Li, "On the SOR-like iteration method for solving absolute value equations," Applied Mathematics Letters, vol. 97, pp. 107-113, 2019.

[5] F. K. Haghani, "On generalized traub's method for absolute value equations," Journal of Optimization Theory and Applications, vol. 166, no. 2, p. 619, 2015.

[6] Y.-F. F. Ke and C. F. Ma, "SOR-like iteration method for solving absolute value equations," Applied Mathematics and Computation, vol. 311, pp. 195-202, 2017.

[7] J. Iqbal, A. Iqbal, and M. Arif, "Levenberg-Marquardt method for solving systems of absolute value equations," Journal of Computational and Applied Mathematics, vol. 282, pp. 134138, 2015.

[8] O. L. Mangasarian, "A generalized Newton method for absolute value equations," Optimization Letters, vol. 3, no. 1, pp. 101-108, 2009.

[9] O. L. Mangasarian and R. R. Meyer, "Absolute value equations," Linear Algebra and Its Applications, vol. 419, no. 2-3, pp. 359-367, 2006.
[10] H. Moosaei, S. Ketabchi, M. A. Noor, J. Iqbal, and V. Hooshyarbakhsh, "Some techniques for solving absolute value equations," Applied Mathematics and Computation, vol. 268, pp. 696-705, 2015.

[11] J. Rohn, "A theorem of the alternatives for the equation $A x+B$ $\mathrm{x}|=\mathrm{b} A x+B| x \mid=b$," Linear and Multilinear Algebra, vol. 52, no. 6, pp. 421-426, 2004.

[12] L. Abdallah, M. Haddou, and T. Migot, "Solving absolute value equation using complementarity and smoothing functions," Journal of Computational and Applied Mathematics, vol. 327, pp. 196-207, 2018.

[13] J. M. Ortega and W. C. Rheinboldt, Iterative Solution of Nonlinear Equations in Several Variables, Academic Press, Cambridge, MA, USA, 1970.

[14] A. Mansoori and M. Erfanian, "A dynamic model to solve the absolute value equations," Journal of Computational and Applied Mathematics, vol. 333, pp. 28-35, 2018.

[15] M. A. Noor, J. Iqbal, K. I. Noor, and E. Al-Said, "On an iterative method for solving absolute value equations," Optimization Letters, vol. 6, no. 5, pp. 1027-1033, 2012. 